\title{
CAMA
}

Centre for Applied Macroeconomic Analysis

\section{The Case for Reform of the RBA's Policy and Communication Strategy}

\section{CAMA Working Paper 3/2020 January 2020}

\section{Bruce Preston}

University of Melbourne

Centre for Applied Macroeconomic Analysis, ANU

\section{Abstract}

At any time, the public should be able to evaluate whether the Reserve Bank of Australia's interest rate decisions are consistent with achieving statutory mandates. The current policy and communication strategy makes this difficult. The mandates, as interpreted by the RBA, fail to provide a clearly identifiable performance benchmark. And the supporting communication strategy falls short of a commitment to explain the economic basis of why and how interest-rate decisions achieve mandated objectives. Examples of both concerns are given from various public documents. Basic reforms would improve the accountability and effectiveness of monetary policy. 


\title{
Keywords
}

Monetary policy, central bank communication, transparency, accountability

\author{
JEL Classification
}

E32, D83, D84

\section{Address for correspondence:}

(E) cama.admin@anu.edu.au

ISSN 2206-0332

The Centre for Applied Macroeconomic Analysis in the Crawford School of Public Policy has been established to build strong links between professional macroeconomists. It provides a forum for quality macroeconomic research and discussion of policy issues between academia, government and the private sector.

The Crawford School of Public Policy is the Australian National University's public policy school, serving and influencing Australia, Asia and the Pacific through advanced policy research, graduate and executive education, and policy impact. 


\title{
The Case for Reform of the RBA's Policy and Communication Strategy*
}

\author{
Bruce Preston ${ }^{\dagger}$
}

8 December 2019

\begin{abstract}
At any time, the public should be able to evaluate whether the Reserve Bank of Australia's interest rate decisions are consistent with achieving statutory mandates. The current policy and communication strategy makes this difficult. The mandates, as interpreted by the RBA, fail to provide a clearly identifiable performance benchmark. And the supporting communication strategy falls short of a commitment to explain the economic basis of why and how interest-rate decisions achieve mandated objectives. Examples of both concerns are given from various public documents. Basic reforms would improve the accountability and effectiveness of monetary policy.
\end{abstract}

Keywords : Monetary policy, central bank communication, transparency, accountability

JEL Codes: E32, D83, D84

${ }^{*}$ I thank Guy Debelle, Chris Gibbs, James Hansen, Warwick McKibbin, Adrian Pagan, Peter Tulip and especially Chris Edmond and Alan Preston for discussions and comments. This document is based on remarks I made at the Centre for Independent Studies' conference, Consilium 2019, in the Plenary Session "The New Financial Landscape - What should be the target of central banks in a disrupted world?" on 30 August 2019. I am currently a Senior Economic Researcher Advisor to the Reserve Bank of Australia and consultant to the Federal Department of Treasury. The usual caveat applies.

${ }^{\dagger}$ The University of Melbourne and Centre for Applied Macroeconomic Analysis. E-mail: bruce.preston@unimelb.edu.au. 


\section{INTRODUCTION}

This article calls for further scrutiny of the Reserve Bank of Australia's policy and communication strategy. I argue that basic reforms would improve policy outcomes. As it stands, the policy strategy, which includes the specific objectives the RBA is mandated to achieve, is imprecise. And the communication strategy, which should provide a public narrative supporting the implementation of the policy strategy, is either absent or not as effective as it could be. Together this limits accountability and transparency of the RBA, risks undermining credibility, and reduces the effectiveness of policy.

I build the argument in two steps. First, I establish there are good reasons to doubt the claim in the Statement on the Conduct of Monetary Policy that "the 2-3 per cent medium-term goal [for consumer price inflation] provides a clearly identifiable performance benchmark". ${ }^{1}$ The argument rests on the fact that reasonable people can disagree about what defines the "medium-term" and, therefore, good performance. Second, at no time does the public have adequate information to determine whether the RBA's failure to achieve its medium-term inflation goal is due to developments beyond its control or to policy error. Which it is matters greatly for the credibility of policy strategy. I provide examples which illustrate how a sharper communication strategy would enhance policy effectiveness and improve accountability and transparency.

While these examples draw from recent public discussion of policy, they identify conceptual issues that apply generally. Importantly, even should future Commonwealth Governments and the RBA revise the agreed upon objectives for monetary policy in a new Statement on the Conduct of Monetary Policy, these communication principles would remain pertinent. Indeed, they are arguably more important as there will inevitably be some imprecision in any formal understanding of the RBA's mandate. Credibility rests on the RBA's commitment to explain its decisions and their consistency with objectives in a way that is part of a coherent strategy over time.

\section{Principles of Design}

Economic policy is complicated. Because private sector behaviour depends on current and future expected policy, policy makers face incentive problems. What is desirable at the time a new policy is implemented may change once market participants internalize that new policy. For example, a government might promise not to tax investment because the resulting distortions lead to an inefficiently small capital stock. But once the capital is installed there are incentives to increase taxes on investment. Similarly, the political cycle tempts use of monetary policy to stimulate the economy for re-election, even though low and stable inflation was an earlier campaign promise.

For these reasons, and others, policy decisions are often delegated to independent agencies. Broadly, with great simplification, there are two design principles. First, the agency must have a fully specified policy framework which determines both the objectives of policy and the framework to achieve those objectives. Second, the agency must be transparent and

\footnotetext{
${ }^{1}$ The Statement on the Conduct of Monetary Policy, an agreement about objectives of policy between the Government and the RBA, can be found at: https://www.rba.gov.au/monetary-policy/framework/stmtconduct-mp-7-2016-09-19.html
} 
accountable. Transparency, achieved through clear communication of the economic framework used to make policy decisions, is the foundation of a credible policy. It is indispensable to accountability and provides incentive for sound policy decisions, incentive to fulfill announced plans for policy.

\section{The Criticism in Two Parts}

At any time, the public should be able to evaluate whether policy decisions are consistent with achieving the statutory mandates to which the RBA is accountable. Currently this is difficult, if not impossible. The source of the problem, when viewed through the lens of the above high-level design principles, is the RBA has an incomplete policy framework. The RBA's interpretation of the Statement on the Conduct of Monetary Policy, if not the document itself, is imprecise. And the supporting economic framework used to make policy decisions cannot be determined from public sources, at least not easily, with some communications at times unhelpful for those wishing to gauge the RBA's thinking about key policy developments.

\subsection{Part I - The Objectives}

The Reserve Bank Act of 1959 states the Reserve Bank of Australia is responsible for the stability of the currency, full employment and the welfare of the people. Let's focus on the first mandate which I call price stability — the third mandate meriting extensive independent discussion. $^{2}$ Price stability is officially interpreted as 2 to 3 percent inflation, on average, over time.

Put aside discussion about whether the numerical objective is an appropriate goal for monetary policy and consider the qualifying phrases "over time" and "on average". The problem is that reasonable people can disagree about what defines "over time" and therefore good performance. Earlier versions of the Statement had the language "over the cycle". Not having had a complete business cycle since 1991 was presumably thought to give the RBA too much flexibility. But "over time" is worse providing no reference period over which the RBA will be evaluated. To what outcomes are we to hold the Bank accountable?

The problem is apparent in the RBA's own evaluation of success or failure. In various public pronouncements the favoured approach is to report average inflation outcomes over ten years and claim that inflation has been '2 point something'. ${ }^{3}$ In testimony to the House of Representatives Standing Committee on Economics on August 9, 2019, Governor Lowe argued: "I think it's too early to tell whether we would have gotten better outcomes if we'd cut interest rates earlier. We have to let this whole cycle play out" - essentially, let's wait and see. Presumably we are to interpret the Governor as saying that at some point inflation will average '2 point something'. A skeptical observer would correctly argue the RBA selects a ten-year period because it is favourable, because it permits various policy mistakes to cancel over time. Indeed, the Statement's failure to be precise permits the RBA to redefine what constitutes success, to shift the goal posts. The notion of "over time" can be adapted to be any period which delivers ' 2 point something'.

\footnotetext{
${ }^{2}$ See McKibbin and Preston (2018) for relevant discussion. Some ideas of this section were also the basis of the opinion piece Preston (2019).

${ }^{3}$ As one example, see Stevens (2016).
} 
But even supposing ten years represents a sensible period, questions remain. For example, there are many ways to achieve ' 2 point something' over ten years. Inflation could be constant at 2.5 percent. It could be 5 percent for five years, and 0 per cent for 5 . It could be 7.5 for five; -2.5 for five and so on. These different scenarios represent fundamentally different economic outcomes and, therefore, different welfare outcomes. Some would entail significant economic costs from unnecessary business fluctuations. And the band itself is perceived by Bank officials as a soft band: because of measurement issues, 1.9 percent is essentially 2 percent. But if so, why not 1.8 , or 1.7 or 1.6 ? If the RBA is to be granted this flexibility in redefining the numerical objective, we must question the purpose of the 2 to 3 percent target band in the first place.

Further questions arise interpreting "on average" which qualifies "over time". Interpreted literally this is a goal for the price-level not the inflation rate. It says that if inflation is zero for five years then it must be at least ' 4 point something' for the next five years for inflation to average ' 2 point something'. A period of under-shooting the target must be matched by a period of over-shooting to deliver a certain minimum price level.

There are sound economic arguments for a price-level target. A price-level target provides greater confidence about the future value of money and in many models predicts long-term inflation expectations to be more firmly anchored, with concomitant falls in the volatility of inflation and real activity. Eggertsson and Woodford (2003) show that when monetary policy is constrained by the zero lower bound on interest rates, anticipation that the central bank is committed to achieve a price-level target will generate expectations of inflation, lower real interest rates and stimulate economic activity. Since leaving the Federal Reserve, Bernanke (2017) has advocated average inflation targeting as a policy to implement the Eggertsson and Woodford recommendations. For Australia, the economic circumstances for which these policy remedies are pertinent are no longer purely hypothetical.

But Debelle (2009) disavows this understanding. The now Deputy Governor argued "the averaging refers more to the distribution of inflation outcomes than to a strict average of CPI outcomes." He continues that the "the bulk of the distribution ... should lie between 2 and 3 per cent". Failure to achieve the inflation target in the past does not lead policy to correct these mistakes going forward. In the words of Stevens (1999) "bygones are, and should be, bygones".

This discussion raises further questions and the Statement says nothing about statistical nuances. If we are not meant to take the language of the Statement literally, what language should we take literally? If the Statement on the Conduct of Monetary Policy doesn't specify the objectives to which the RBA is accountable, what public document does?

Because the RBA's interpretation of the objective is vague, it is difficult for the public to hold the Bank accountable. There is always scope to redefine what constitutes successful policy. Dr Andrew Leigh asked of Governor Lowe an illustrative question: "How many more years of undershooting would be required before the Reserve Bank stopped attributing that undershooting to one-off forecasting mistakes?" "Without a clear understanding of the framework being used to achieve those objectives, it is impossible to know whether deviations from target are because of unanticipated developments, or policy mistakes. The remainder

\footnotetext{
${ }^{4}$ See page 29 of Commonwealth of Australia, House of Representatives (2019), Standing Committee on Economics, Reserve Bank of Australia Annual Report, August 9.
} 
of the article explores why knowledge of the policy strategy is critical to a credible and accountable monetary policy.

\subsection{Part II — The Strategy}

An important idea in modern monetary policy is the distinction between goal independence and instrument independence. There is broad consensus that central banks should take their mandates from democratically elected representatives but have flexibility in the choice of policy strategy to achieve these mandates. In the language of Debelle and Fischer (1994) there should be "instrument independence" but not "goal independence".

Consistent with this principle, Australia's inflation-targeting framework grants the RBA considerable discretion in its choice of policy strategy. This flexibility acknowledges the desirability of short-run stabilization of real activity as a goal of policy, alongside price stability. The compatibility of these two objectives requires a high degree of transparency. Consider a cost-push shock that raises inflation and unemployment. Central banks which explain why and how their policy decisions are compatible with achieving their mandates will be able to achieve better short-term stabilization of the macro-economy. Despite observing higher inflation, medium-term expectations of inflation will remain anchored because it is understood that reducing inflation more quickly would lead to prolonged rises in unemployment. That the public understands these outcomes are consistent with a coherent policy strategy ensures price stability in the medium term is a reasonable expectation. Currently the Bank's communication strategy falls well short of this ideal.

Central banks control overnight rates in interbank markets to influence long-term rates relevant to spending and investment plans. It is not the current cash rate that matters for economic management, but rather the expected future path of cash rates that matter for long-term interest rates. Monetary policy largely operates through managing expectations, making communication central to good policy and credibility. As Woodford (2007) explains, inflation targeting frameworks are distinguished from other monetary regimes, such as a gold standard or a rules based approach, by their commitment to explain how policy decisions are made and how they are consistent with medium-term objectives. Inflation targeting exchanges 'verification' - observable adherence to convertibility or a prescribed rule with a policy strategy that is 'visible' to the public.

Without this commitment, the notion of credibility is empty of content. Communication of the policy framework permits market participants to evaluate the extent to which the RBA's actions conform to past commitments, and to distinguish departures from these plans because either: i) economic circumstances evolved in a way that was not anticipated; or ii) because they failed to deliver on their commitments, pursuing actions that are inconsistent with mandated objectives. The only way we can make inferences of this kind is by being well informed about the policy framework.

Currently there is no single public document that, over time, consistently describes the monetary policy framework and the evolution of thinking about key macroeconomic quantities, such as the natural rate of unemployment, in words or otherwise. There is certainly some information about the policy strategy learned from experience, as well as various speeches, Bulletin articles, and other publications that are helpful in this regard. But they collectively fall short of a clear coherent public statement of the policy strategy. 
Institutions build credible reputations in the long-run by taking actions that are not in their short-run interest - i.e., by demonstrating that they can take hard decisions. Taking credit when things are going well and blaming external factors when they are not going so well is antithetical to building credibility. And there will certainly be times when the RBA will want, and rightly so, to point to factors beyond their control, which influence inflation outcomes - but why should we believe them? If the RBA has no history of fulfilling past commitments, then claims of this kind risk being interpreted as policy error, rather than exceptional circumstance.

Central banks often turn this logic on its head. They argue that communicating a policy strategy will constrain what they can do if circumstances arise where policy needs to change radically. But this misses the point entirely. First, reneging on past commitments should be costly. If it wasn't, then the ideas of commitment and credibility would have little content. Second, if the policy strategy has in fact been properly communicated, then the public will understand the change in policy is justified by that strategy.

Experience of other central banks during the Global Financial Crisis reveals the importance of effective communication strategies. When conventional monetary policy becomes constrained by the zero lower bound on interest rates, a central bank's influence on long-term interest rates depends heavily on expectations about future policy; on how the central bank is anticipated to behave when no longer constrained. For example, the Federal Reserve in the United States refined its communication strategy over the course of recovery, becoming progressively more precise about the circumstances under which it would raise interest rates - see Bernanke (2013) for a discussion. A reasonable interpretation is that the initially vague statements about future policy were ineffective. They did not represent a credible commitment to a future course of action.

Failure to develop an effective communication strategy therefore has costs, particularly in unfamiliar times, in circumstances in which people have little experience with the challenges confronting policy. Because the narrative deployed by the RBA lacks clarity, there will be no track record of making credible commitments. This will constrain the efficacy of new policy initiatives, such as those many advanced economies have had to experiment with in the past decade, should economic circumstances require them.

Once these ideas are understood, it is clear why even if we 'wait and see' we can't judge whether policy has been a success or failure unless we have a clear sense of the framework being applied; 'wait and see' is an unhelpful response when people are trying to understand the RBA's own thinking about how it evaluates outcomes. Indeed, greater clarity of the policy strategy would largely overcome earlier criticisms of the Statement on the Conduct of Monetary Policy. A clear public narrative about policy strategy, when applied consistently over time, would constrain the ability of the RBA to redefine success either by shifting emphasis from one mandate to another, or by changing the period over which average inflation outcomes are to be evaluated. Shifting the goal posts in this way is incompatible with a policy strategy based on a coherent and consistent set of economic principles.

\section{Examples of Poor Communication}

Let me offer four concrete examples that highlight relevant concerns. 


\subsection{Example 1: Using Market-Based Expectations}

The Statement on Monetary Policy publishes forecasts of GDP growth, CPI inflation and unemployment conditional on market expectations of future interest rates. ${ }^{5}$ While seemingly sensible it compromises both macroeconomic control and credibility of the central bank. Central Banks use market expectations to avoid discussing publicly their own views about the future path of interest rates. But doing so leads to conceptual and practical difficulties. An interest rate decision procedure based on market expectations of interest rates is incomplete. If the projections for inflation and unemployment conflict with achieving the RBA's mandates, it is unclear what principles guide alternative choices of policy. The approach is therefore inconsistent with a commitment to explain and justify the economic basis of interest rate decisions.

One principle for choosing the interest rate appears to be based on the idea that should the projections of inflation be below target, conditional on market expectations, interest rates should be lowered today. But this falls well short of providing a strategy for choosing a path of interest rates, as required in forward-looking economic models. ${ }^{6}$ To determine interest rates today, such models require having a view about how interests rates will be set into the distant future. Moreover, using this approach to make policy decisions provides no information about how the RBA evaluates any conflict to achieving price stability with the full employment and welfare mandates. But even supposing the RBA does have an internal strategy to determine an interest rate path to achieve the price-stability mandate over some horizon, the approach will be intertemporally inconsistent. Should the economy evolve exactly as the RBA anticipates, with no new information about the state of the economy, the decision procedure will lead to a different choice of interest rate path in subsequent policy meetings. This is a well-known problem with formulating inflation targeting with a fixed horizon. ${ }^{7}$

A further concern is the use of market expectations in the RBA's own internal discussions and public justification of its actions will tend to confirm market views, even if they are wrong. Because market-based expectations exist independently of how the economy develops, standard forward-looking economic models imply indeterminacy of equilibrium. ${ }^{8}$ This is an example of the classic result of Sargent and Wallace (1975) which demonstrates that policies which assume interest rates are exogenous to economic developments lead to multiple equilibria. In models with backward-looking expectations, such as adaptive expectations, policy based on exogenous interest rate paths often predict explosive inflation dynamics. ${ }^{9}$ Either case compromises inflation control.

Because market-based projections are independent of inflation outcomes they are uninformative about what the RBA plans to do and how it will react to economic developments. What people want to know is the policy strategy: what is the systematic response of policy to economic developments, sometimes called the reaction function. This knowledge permits

\footnotetext{
${ }^{5}$ See Table 1, page 60, Reserve Bank of Australia, "Statement on Monetary Policy", August 2019. The Statement on Monetary Policy should not be confused with the earlier referenced Statement on the Conduct of Monetary Policy.

${ }^{6}$ See, for example, the RBA's own models of the economy Rees, Smith, and Hall (2016) and Ballantyne, Cusbert, Evans, Guttmann, Hambur, Hamilton, Kendall, McCririck, Nodari, and Rees (2019).

${ }^{7}$ See Woodford (2005) and Woodford (2007).

${ }^{8}$ The RBA's own internal models are subject to this concern — see footnote 6 .

${ }^{9}$ See, for example, Evans and Honkapohja (2003) and Preston (2005).
} 
the public to form expectations that are consistent with the policy objectives and strategy of the Bank. Said differently, it anchors expectations about inflation and other variables, providing more precise control of the macro-economy. When market participants hold different views about future developments what is important to them is understanding what their views mean for the future conduct of policy. But without clarity about policy strategy, such inference is impossible.

Good policy should therefore be predictable. While central banks can't always be right about the exact path of economic developments, they can be right about how they will adjust policy should certain developments occur. The uncertainty which the RBA can resolve is how it plans to act. That is, it can clarify its policy strategy: how will it respond to economic developments and how it weighs different considerations and risks when thinking about future interest rate decisions. A communication strategy built on the idea of 'this is what we plan not to do' will be ineffective if not costly.

\subsection{Example 2: Financial Stability - The Third Mandate}

In recent years the RBA has justified its actions in terms of the so called third mandate, the welfare of the Australian people. ${ }^{10}$ Interest rates were kept higher than otherwise out of concern for housing market developments. The thinking was that lower interest rates would further weaken household balance sheets to compromise the first two mandates. ${ }^{11}$

Putting aside the fact that there are grounds to be concerned with an independent agency that isn't democratically elected having latitude to make judgements about what is and what isn't in the interests of the Australian people, there is also the concern of how we are to understand the context of this objective relative to the other two mandates. Prior to the interest rate reductions from 1.5 per cent to 0.75 per cent many asked: at what point would the RBA relinquish its concerns for financial stability and attend inefficiently high unemployment and inflation systematically below target? There was no way to make informed judgement about this, because there was little information about the framework for policy deliberation, and certainly no way to judge the priorities given to each of its three mandates.

As one example, successive Statements on Monetary Policy do not build a clear narrative about the evolution of thinking about the natural rate of unemployment, and, therefore, the circumstances under which policy might become concerned about labour market developments, rather than being concerned about potential financial stability implications arising from household balance sheets. A related concern is what it means to pursue financial stability as a third mandate, the welfare of the Australian people - how do we measure this? Almost any policy could be justified in these terms, raising legitimate concerns about how we are to hold the RBA accountable. No one would claim the RBA should not have financial stability concerns. But this does not absolve the RBA of providing some quantitative guidance as to what constitutes good policy. ${ }^{12}$ Prior to the recent policy rate reductions

\footnotetext{
${ }^{10}$ See Lowe (2017).

${ }^{11}$ See, for example, Lowe (2017).

${ }^{12}$ There is also the question of what the RBA thinks about a large body of research arguing that financial stability is an inappropriate objective for monetary policy. See Svensson (2017) and Saunders and Tulip (2019) for discussion and review of this research.
} 
which gave emphasis to achieving full employment it was impossible for market participants to gauge the RBA's thinking on this trade-off.

The RBA's own discussion about this is a source of confusion. In his 2019, August 9, testimony Governor Lowe declared the RBA did not pursue a 'lean against the wind' policy. Yet public announcements suggest otherwise. Indeed, Lowe (2017) justifies policy on the ground that: "For some time, the Board has been seeking to balance the benefits of stimulatory monetary policy with the medium-term risks associated with high and rising levels of household debt." This highlights confusion about the ultimate goals of policy and the intermediate objectives to achieve those goals. It also reflects loose language that stems from the absence of a coherent framework.

The RBA can't have it both ways. In resorting to the third mandate it either pursued a lean against the wind policy or didn't. If it did act on the grounds of financial stability, this is leaning against the wind. If it didn't, then there was no need to invoke the third mandate. Discussion of good policy could have been cast solely in terms of the consequences of interest rate changes for price stability and full employment, without muddying the waters with a third mandate (that is, without confusing intermediate and ultimate goals of policy). Such language and change in emphasis lead to concern that the priorities of the RBA have shifted in a fundamental way. It also reads suspiciously like an excuse for failure to meet the first two mandates. And if it wasn't this time, comfort in invoking the third mandate, which is inherently un-measurable, may lead to temptation in the future.

\subsection{Example 3: Forward Guidance — LOW FOR LONG}

In the same testimony, Governor Lowe, having acknowledged an important lesson from recent international experience is "communication wasn't as clear and consistent as it could have been, and it's caused problems", states that: "we're expecting interest rates to stay low for a very long time. We haven't said 'until X date' or 'until these conditions are met' but we're trying to be transparent".

This fails to understand the central lesson from the Federal Reserve's evolving use and understanding of forward guidance. The statement "we're expecting interest rates to stay low for a very long time" is a forecast, not policy strategy. Bernanke (2013) argues the Federal Reserve Open Market Committee judged language of this kind failed to convey their intentions for policy and had limited stimulatory effect through expectations. The Committee progressively moved to more state-contingent declarations, to be more explicit about when and how economic circumstances would engender a change in policy. An empirical literature provides support for this view and documents the efficacy of forward guidance in lowering long-term interest rates - see, among many others, Woodford (2012) and Swanson and Williams (2014).

Variants of the language "low for a very long time" now appear in the announcement and Minutes of recent interest rate decisions. When the RBA inevitably changes interest rates - and it will, up or down - it will justify such actions saying that we never said interest rates wouldn't change, we just didn't say when or why they would change. Such announcements grant plausible deniability, and market participants know this. They are unlikely to have the desired stimulatory effect and risk credibility. An objection might be that long-term interest rates are already at historical lows so forward guidance has limited 
scope as a policy tool. But this is short-sighted. When economic growth resumes there may still be advantages to keeping long-term interest rates low to ensure a sustained recovery. Having a history of talking clearly about future policy intentions will provide greater control of long-term expectations and interest rates.

\subsection{Example 4: The Minutes - Justifying Policy Decisions}

After each policy decision the RBA provides a policy announcement and later the minutes of the policy meeting. Both documents provide an overview of domestic and international economic and financial conditions, concluding with a summary and justification of the policy decision. What is notable about the justification is the absence of a detailed discussion of the economic reasoning and mechanisms by which policy will achieve objectives. The language is often vague and evasive, using phrases such as "gentle turning point" and "consistent with a gradual return to target". The Minutes almost never state the economic channels by which policy decisions will deliver these outcomes. Perhaps most importantly, we are never told why an alternative choice of interest rate would not achieve objectives in a more effective manner.

Take the November 2019 Statement on Monetary Policy and the November 5 Minutes. Together the two documents raise basic questions about the conduct of policy. The projections in the Statement on Monetary Policy imply inflation will be below target in roughly two years. At the same time, unemployment is expected to remain above the natural rate of unemployment. Given these forecasts, an obvious question is how can the decision to leave rates unchanged be compatible with achieving price stability and full employment. After all, in circumstances of insufficient demand lower interest rates would increase both inflation and employment.

One interpretation is the RBA thinks further interest rate reductions will lead to one or both of inflation and employment to be below target for a longer duration than predicted under the current policy. If so, the economic reasoning that justifies this conclusion should be explained, with reference to the projections provided by the Statement on Monetary Policy and explicit mention of why current economic circumstances are not one of weak aggregate demand. The Minutes suggest an alternative explanation that reducing interest rates rapidly might convey undue pessimism about the state of the economy, with negative effects on confidence. The case for inaction then rests on the public never becoming aware that economic conditions are in fact weak and that they somehow would not benefit now from lower interest rates, though will at some later date.

While it is entirely plausible that confidence effects might reduce the elasticity of demand to interest rate changes, such effects are unlikely to change the sign of effect. This type of argument is reminiscent of 'keeping your powder dry', a policy recommendation which finds almost no support in Old or New Keynesian models for policy analysis. So if the RBA does lower rates further, as markets expect, we are left again to ask: what principles guide policy?

\section{Conclusions}

The documents from which these examples are drawn frame the public's understanding of the Reserve Bank's objectives and actions. While they contain useful information, it should 
be clear that, in certain respects, these documents neither provide a "readily identifiable performance benchmark", nor contain sufficient information to evaluate whether RBA policy actions are consistent in achieving those benchmarks. This limits democratic accountability of one of our most important public institutions and risks the credibility of monetary policy.

There should be a review to address these issues. Other central banks have dealt with these types of criticism and have inflation reports that provide a foundation upon which Australian discussion could build. ${ }^{13}$ For many issues there would be no need to chart unknown territory. However, for those issues that do, a review should ask why certain communication strategies haven't been adopted abroad, and whether those arguments pass muster here. A reluctance to be evaluated and therefore accountable is unacceptable. The relevant criterion should be whether changes to the policy and communication strategy serve the commitment to explain policy decisions.

With the exception of the Statement on the Conduct of Monetary Policy, the public documents that I have discussed have largely emerged from internal decisions to improve transparency. From this perspective, dealing with my concerns would be a natural evolution in this effort. Importantly, these reforms would not require any legislative changes to implement and could be dealt with at the RBA's own initiative. Because the objectives of monetary policy should reflect democratic outcomes, changes to the Statement of the Conduct of Monetary Policy would require a broader discussion and should meet the requirements of public transparency. Possible changes should focus on what defines successful policy. The RBA's interpretation of "over time" and "on average" are potential points of concern. But as argued, a policy strategy that is 'visible' to the public would likely resolve the ambiguity inherent in this language.

There is little doubt that inflation targeting has served Australia well since the early 1990s. The RBA should receive recognition for establishing this new monetary regime and building its credibility. But these achievements should neither protect the RBA from public scrutiny and accountability, nor prevent us from asking whether we can do better. Credibility is not a vacuous concept to be paid lip-service to - it has substantive content which lies at the heart of good policy and underwrites the investment in the institution itself. The examples beg the question: does the RBA not want to be credible?

\footnotetext{
${ }^{13}$ See, for example, the Norges Bank's Monetary Policy Report with Financial Stability Assessment. The Report provides a statement of the principles guiding policy, including how perceived trade-offs influence decisions; how policy decisions are consistent with forecasts and achieving mandated objectives; and how forecasts change in response to new information over time. This Report is given four times a year.
} 


\section{REFERENCES}

Ballantyne, A., T. Cusbert, R. Evans, R. Guttmann, J. Hambur, A. Hamilton, E. Kendall, R. McCririck, G. Nodari, and D. Rees (2019): "MARTIN Has Its Place: A Macroeconometric Model of the Australian Economy," RBA Research Discussion Papers rdp2019-07, Reserve Bank of Australia.

Bernanke, B. S. (2013): "Communication and Monetary Policy: a speech at the National Economics CLub Annual Dinner, Herbert Stein Memorial Lecture, Washington D.C., November 19, 2013," Speech 563, Board of Governors of the Federal Reserve System (U.S.).

(2017): "Monetary Policy in a New Era," Discussion paper, Brookings Institution, unpublished manuscript.

Debelle, G. (2009): "The Australian Experience with Inflation Targeting," Speech at Banco Central do Brasil XI Annual Seminar on Inflation Targeting, 15 May.

Debelle, G., And S. Fischer (1994): "How independent should a central bank be?," in Monetary Policy in a Low Inflation Regime, pp. 195-225.

Eggertsson, G., And M. Woodford (2003): "The Zero Bound on Interest Rates and Optimal Monetary Policy," Brookings Papers on Economic Activity, pp. 139-211.

Evans, G. W., and S. Honkapohja (2003): "Expectations and the Stability Problem for Optimal Monetary Policies," Review of Economic Studies, 70(4), 807-824.

Lowe, P. (2017): "Remarks at Reserve Bank Board Dinner," Reserve Bank of Australia, 5 September.

McKibbin, W., And B. Preston (2018): "It's not the Reserve Bank's job to pick winners and losers," Australian Financial Review.

Preston, B. (2005): "Learning About Monetary Policy Rules when Long-Horizon Expectations Matter," International Journal of Central Banking, 1(2), 81-126.

_ (2019): "Loose language spares the RBA from real assessment," Australian Financial Review.

Rees, D. M., P. Smith, and J. Hall (2016): "A Multi-sector Model of the Australian Economy," The Economic Record, 92(298), 374-408.

Sargent, T. J., and N. Wallace (1975): "Rational Expectations, the Optimal Monetary Instrument, and the Optimal Monetary Supply Rule," Journal of Political Economy, 83, $241-254$.

Saunders, T., And P. Tulip (2019): "Cost-benefit Analysis of Leaning against the Wind," RBA Research Discussion Papers rdp2019-05, Reserve Bank of Australia. 
Stevens, G. (1999): "Six Years of Inflation Targeting," Address to the Economic Society of Australia, 20 April.

(2016): "An Accounting," Address given to the Anika Foundation Luncheon, 10 August.

Svensson, L. E. (2017): "Cost-benefit analysis of leaning against the wind," Journal of Monetary Economics, 90(C), 193-213.

Swanson, E. T., And J. C. Williams (2014): "Measuring the Effect of the Zero Lower Bound on Medium- and Longer-Term Interest Rates," American Economic Review, 104(10), 3154-3185.

Woodford, M. (2005): "Central bank communication and policy effectiveness," Proceedings - Economic Policy Symposium - Jackson Hole, (Aug), 399-474.

(2007): "The Case for Forecast Targeting as a Monetary Policy Strategy," Journal of Economic Perspectives, 21(4), 3-24.

(2012): "Methods of policy accommodation at the interest-rate lower bound," Proceedings - Economic Policy Symposium - Jackson Hole, pp. 185-288. 